\title{
Tutorial: How to access BDJ Team CPD
}

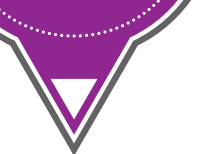

\section{BDJ TEAM CPD INSTRUCTIONS}

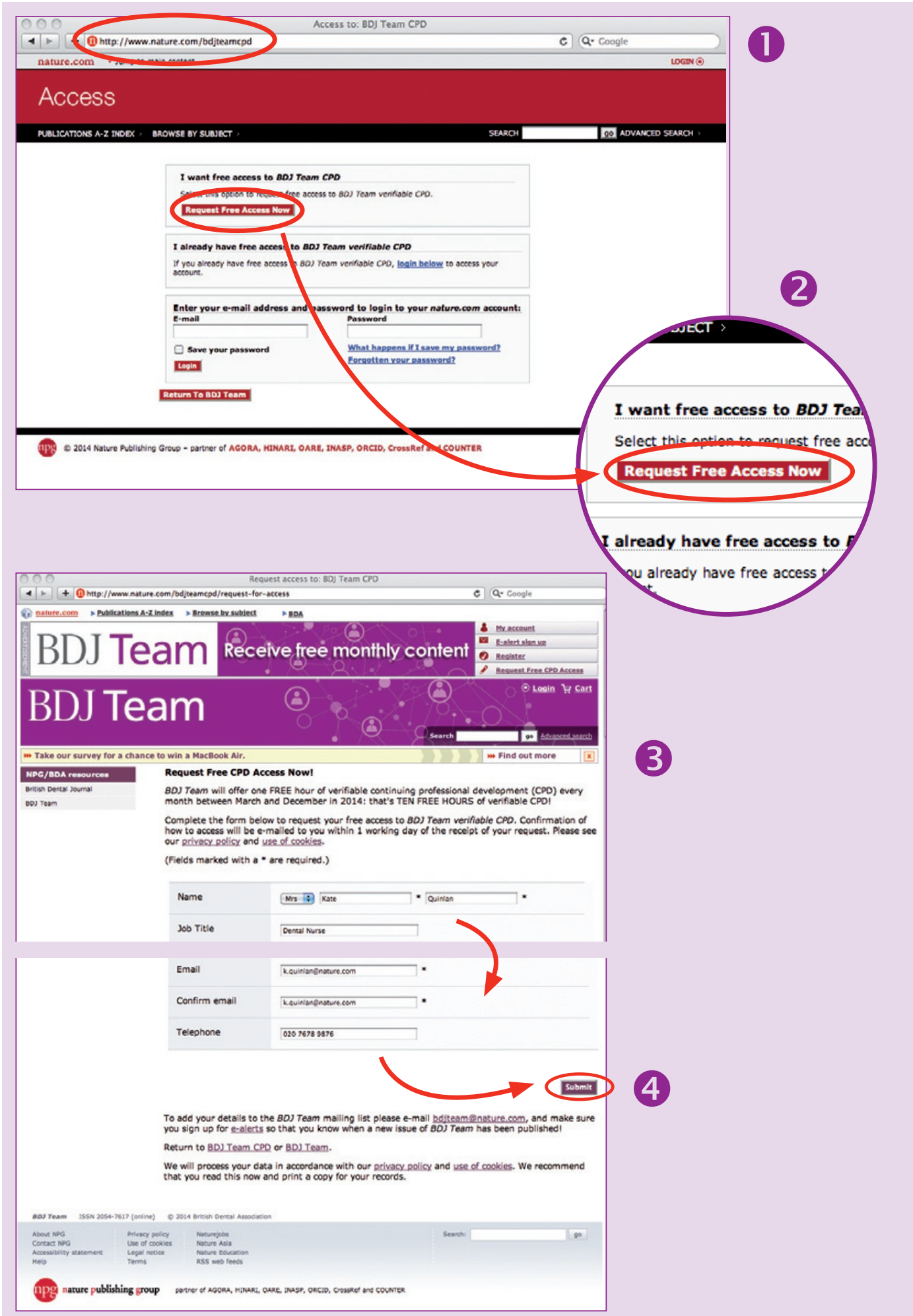

(1) Step 1: Go to www.nature.com/ bdjteamcpd

(2) Step 2: Click on 'Request Free Access Now

(3) Step 3: Fill in the form

(4) Step 4: When you have filled in the form, click on 'submit' 


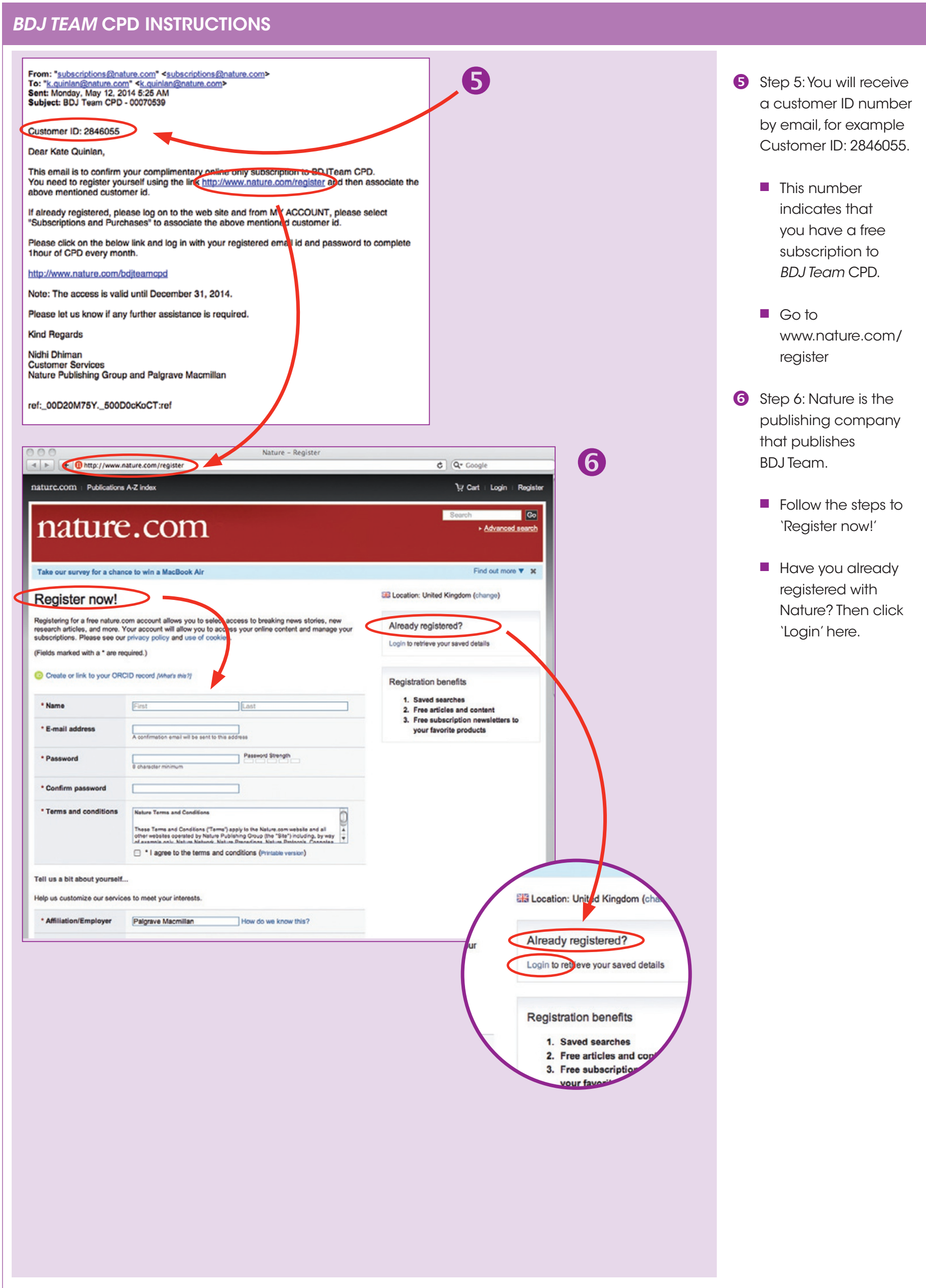




\section{BDJ TEAM CPD INSTRUCTIONS}

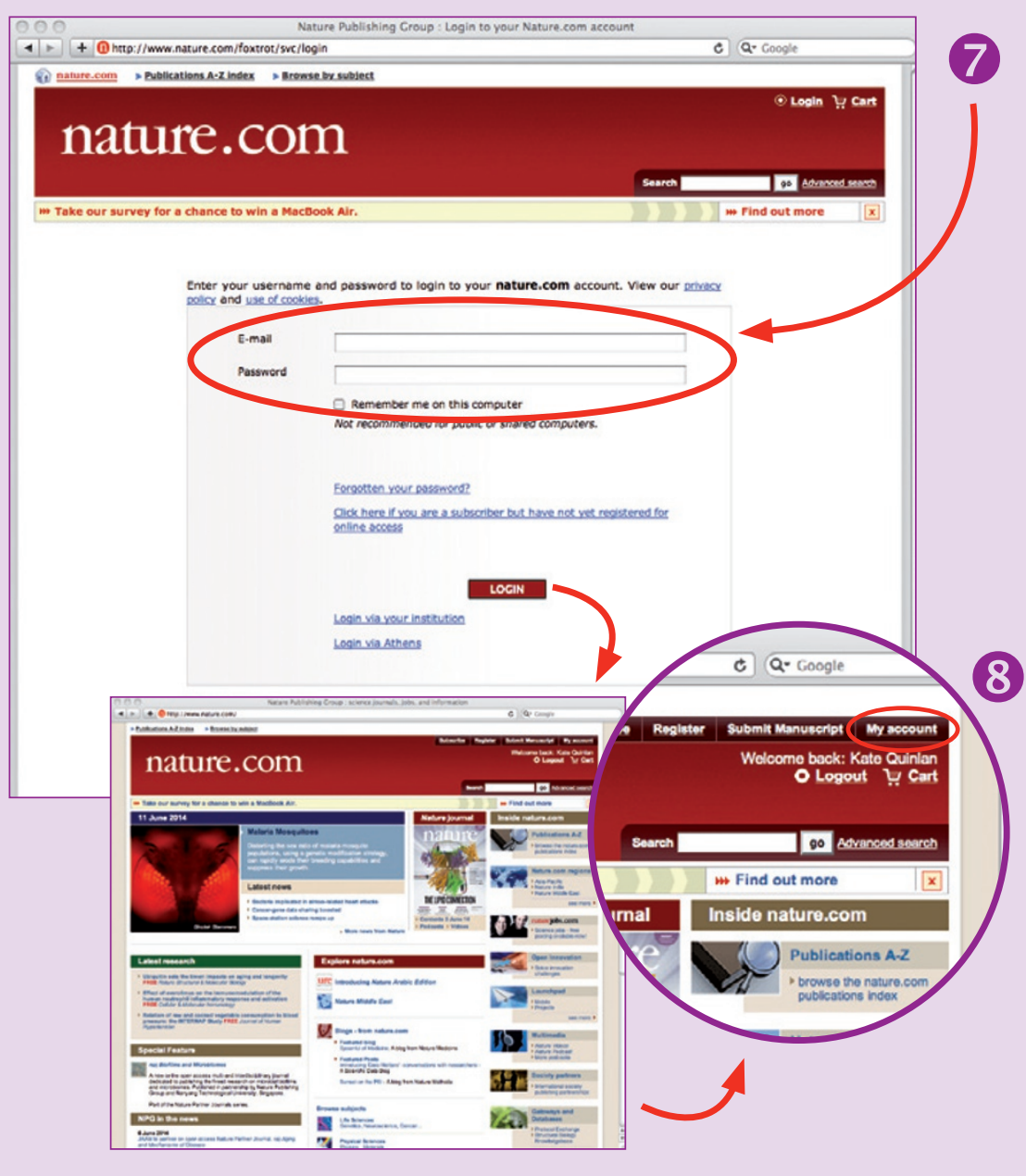

7 Step 7: Log-in to Nature with your email address and password

8 Step 8: When you are logged in, click on 'My account' (top right)

9 Step 9: Click on 'Subscriptions and purchases

(10) Step 10: Click on 'Want to manage a subscription not shown above?'

(11) Step 11:You will see a box that says 'Customer ID'. Enter your customer ID in this box and click 'Submit'

9

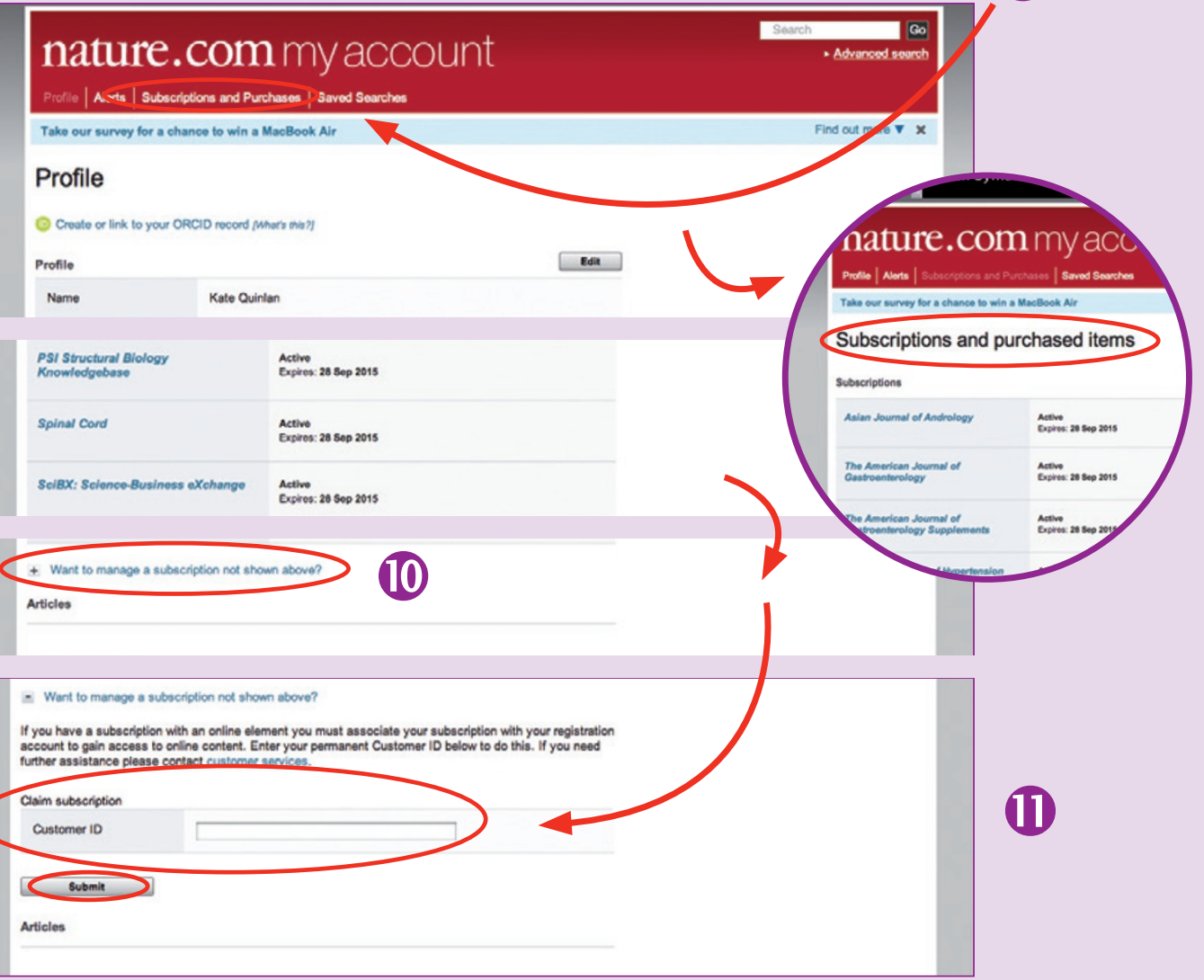




\section{BDJ TEAM CPD INSTRUCTIONS}

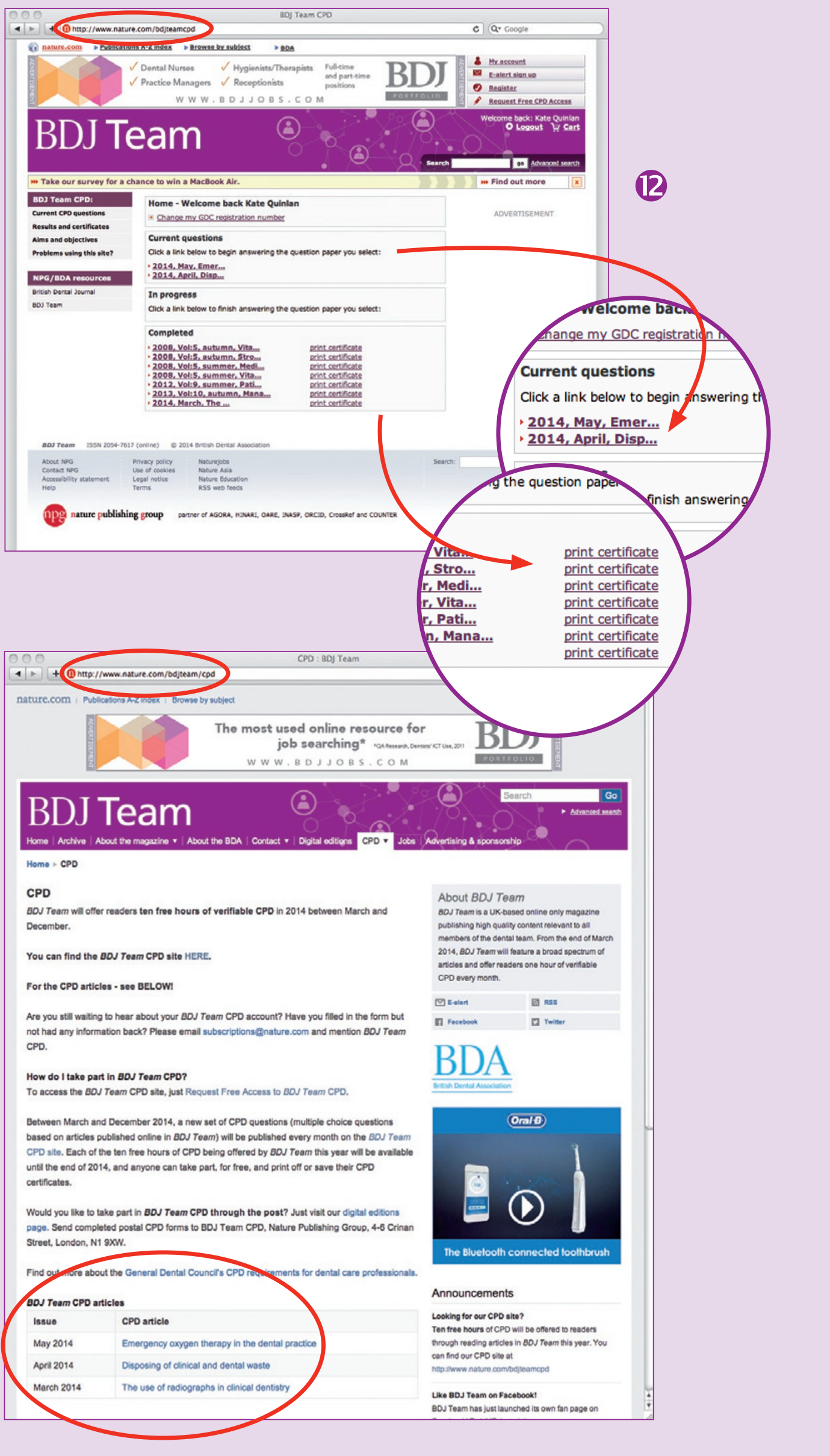

(12) Step 12:Your BDJ Team CPD free subscription is now set up. Go to www.nature.com/ bdjteamcpd to answer the CPD questions and to save or download your CPD certificates!

FOR FUTURE REFERENCE

You can find BDJ Team CPD articles here:

www.nature.com/

bdjteam/cpd

You can find BDJ Team CPD questions here:

www.nature.com/

bdjteamcpd 